Abstracta Iranica Abstracta Iranica

Revue bibliographique pour le domaine irano-aryen

Volume 42-43 | 2021

Comptes rendus des publications de 2019-2020

\title{
Meryem Sebti, Daniel De Smet (dir.). Noétique et théorie de la connaissance dans la philosophie arabe du $\mathrm{IX}^{\mathrm{e}}$ siècle XII ${ }^{\mathrm{e}}$ siècle
}

\section{Mathieu Terrier}

\section{OpenEdition}

Journals

\section{Édition électronique}

URL : https://journals.openedition.org/abstractairanica/54314

DOI : 10.4000/abstractairanica.54314

ISSN : 1961-960X

Éditeur :

CNRS (UMR 7528 Mondes iraniens et indiens), Éditions de l'IFRI

\section{Référence électronique}

Mathieu Terrier, « Meryem Sebti, Daniel De Smet (dir.). Noétique et théorie de la connaissance dans la philosophie arabe du Ix ${ }^{\mathrm{e}}$ siècle xı ${ }^{\mathrm{e}}$ siècle », Abstracta Iranica [En ligne], Volume 42-43 | 2021, document 1, mis en ligne le 30 décembre 2021, consulté le 16 décembre 2022. URL : http://

journals.openedition.org/abstractairanica/54314 ; DOI : https://doi.org/10.4000/abstractairanica. 54314

Ce document a été généré automatiquement le 16 décembre 2022.

Tous droits réservés 


\title{
Meryem Sebti, Daniel De Smet (dir.). Noétique et théorie de la connaissance dans la philosophie arabe $\mathrm{du} \mathrm{IX}^{\mathrm{e}}$ siècle XII siècle
}

\author{
Mathieu Terrier
}

\section{RÉFÉRENCE}

Meryem Sebti, Daniel De Smet (dir.). Noétique et théorie de la connaissance dans la philosophie arabe du $\mathrm{IX}^{e}$ siècle XII ${ }^{e}$ siècle. Paris : Vrin, Études musulmanes LII, 2019, 410 p., ISBN : 978-2-7116-2854-4

1 Cet ouvrage collectif rassemble huit spécialistes chevronnés de philosophie en langue arabe sous la direction de M. Sebti, spécialiste d'Avicenne, et de D. De Smet, spécialiste de la philosophie ismaélienne, pour faire un point aussi éclairant que bienvenu sur l'un des chapitres les plus centraux mais aussi les plus complexes de la philosophie en Islam. La profusion de théories sur l'intellect ('aql), la connaissance et les facultés de l'âme, embrassant les domaines de la psychologie, de la cosmologie et de la métaphysique, sous la plume de philosophes de langue arabe, de religion musulmane et pour nombre d'entre eux de culture iranienne, trouve sa source dans un passage fort abscons du Traité de l'âme d'Aristote (De Anima, III, 4-5) à l'origine du concept d'Intellect agent (noûs poiétikos), réinterprété selon le paradigme émanationniste du néoplatonisme. Cet ouvrage, appelé à être suivi d'un second volume, présente un premier pan de l'histoire de ces concepts et des problèmes afférents en Islam, allant des débuts de la falsafa au premier héritage d'Avicenne.

Une première partie porte sur les traductions gréco-arabes, celle de Plotin (la Théologie dite d'Aristote), à l'origine de la «noétique » arabe (C. D'Ancona), et celles des courts traités sur l'âme d'Aristote, les Parva Naturalia (R. Hansberger). La deuxième partie 
porte sur al-Kindī et Abū Bakr al-Rāzī (P. Adamson), ce dernier chapitre faisant le point sur la doctrine originale, controversée et mal connue de ce penseur iranien illustre pour son œuvre médicale. La troisième partie comprend deux contributions de D. De Smet sur les œuvres des philosophes ismaéliens Abū Ya'qūb al-Siğistānī et Ḥamīd al-Dīn al-Kirmānī ainsi que des fameux IĤwān al-Ṣafā' (les Frères de la Pureté) ; l'A. établit clairement la double empreinte du néoplatonisme et de l'imâmologie shi'ite sur ces œuvres, prolongeant et illustrant des analyses d'un précédent ouvrage (La philosophie ismaélienne: un ésotérisme chiite entre néoplatonisme et gnose, Paris : Le Cerf, coll. "Les conférences de l'École Pratique des Hautes Études », 2012). Enfin, la quatrième partie porte principalement sur les deux philosophes majeurs que sont al-Fārābī et Ibn Sīnā (Avicenne) ainsi que sur leurs disciples et successeurs immédiats. L'épais dossier de la noétique dans l'œuvre d'al-Fārābī est étudié par Ph. Vallat qui développe l'idée d'une "ontogenèse de l'intellect» ou d'une "transformation du connaître en être ». La théorie de l'âme et de la connaissance d'Avicenne, présentée par M. Sebti, débouche sur des réflexions originales relatives à la prophétie et à l'eschatologie. Des chapitres sont également consacrés à des philosophes moins connus, souvent moins originaux mais dignes d'intérêt, comme Abū l-Ḥasan al-'Āmirī (E. Wakelning), Abū l-'Abbās al-Lawkarī (R. D. Marcotte), Bahmanyār b. al-Marzubān (M. Sebti) et Abū l-Barakāt al-Bag̉dādī (R. D. Marcotte).

Dans chaque chapitre, la présentation suit généralement un ordre thématique analogue, étudiant successivement l'âme humaine, son origine, ses facultés (en particulier la rationnelle), son rapport avec le corps ; l'Intellect agent et son rôle dans l'actualisation de l'intellect humain; la noétique en relation avec la cosmologie; la prophétie et l'eschatologie. Suit une anthologie de textes en traduction française ou anglaise, accompagnée d'un glossaire bilingue (arabe-français ou arabe-anglais) des termes et expressions philosophiques. Un index nominum, un index rerum et un index des versets coraniques cités viennent clore cet ouvrage conçu comme un véritable manuel. Par sa précision, sa clarté et sa cohérence, cette publication offre donc au lecteur curieux de philosophie un panorama à la fois ample et cohérent, à l'historien de la philosophie une riche matière comparative, et au chercheur ou traducteur en philosophie arabe un précieux instrument de travail.

\section{AUTEURS}

\section{MATHIEU TERRIER}

CNRS, LEM, Paris 